\title{
It has been an extraordinary experience, but the time has come to pass the baton
}

Mogensen 1 compared the science enterprise to a marathon with scientists needing to be prepared for long-distance running, beginning from raising one original research question to finally publishing the results answering it. The process of publishing the results can be itself compared to a relay race, where each team member runs in sequence a segment of a predetermined distance, handing a baton to the next team runner. After a manuscript is submitted to a scientific journal, it will pass from hand to hand, in general, many times until eventually being published. Indeed, the editorial process is much more complex, encompassing multiple actors and procedures that do not necessarily occur in a linear direction. But in common to a relay race, and probably even more, it demands coordination. The role of the Editor-in-chief is setting the editorial policy and coordinating the editorial process. It is not an easy task, particularly in the context of rapid changes of the editorial enterprise, both due to the continuing evolution of digital technology and the movement towards Open Science.

Being part of the trio of CSP's Editors-in-chief has been one of the most exciting activities in my academic carrier. Sharing this job with Claudia Travassos, Marilia Sá Carvalho and Luciana Dias de Lima, has made it even more special. Despite our different backgrounds and professional trajectories, we see eye to eye on a Public Health scientific journal's role in fostering an ethical, cooperative, and meaningful research enterprise.

After nine years occupying this honored position, I realized that the time has come to change gears and dedicate more energy to new projects in Population Data Science. I would like to express my deep gratitude to the direction of the Sergio Arouca National School of Public Health, Oswaldo Cruz Foundation (ENSP/Fiocruz), Carlos Coimbra Jr., Claudia Travassos and Marilia Sá Carvalho for invinting me to occupy, for the first time, the position of the CSP's Co-Editor-in-chief from outside the Fiocruz faculty. Likewise, I want to thank Carolina Ribeiro, Leandro Carvalho, Marcia Pietrukowicz, Carla Alves, Eduardo Ribeiro Pina, Fábio Souza, Giane Caputo and Rafael Pacheco, members of the executive staff, whose competent and dedicated work is essential for the quality of CSP's editorial process. Finally, in the person of Luciana Correia Alves, to whom with pleasure I pass the baton, I thank all CSP's Associated Editors, reviewers, authors, and readers. Luciana Alves,
${ }_{1}^{1}$ Instituto de Estudos em Saúde Coletiva, Universidade Federal do Rio de Janeiro, Rio de Janeiro, Brasil. 
a professor at the Department of Demography at Campinas State University (UNICAMP), has a solid background in Demography, Epidemiology, and Population Data Science. Producing a coherent body of innovative research in all these fields, she will undoubtedly pollinate CSP with new fresh ideas.

One of the features that I most enjoy in being a member of the CSP team is our social connectedness. Alon 2 considers social connectedness a fundamental factor to build motivated and successful work teams. In his view, "our connection to a community and a culture provides us context and empathy during our struggles, celebration, and acknowledgment during our successes" 2 (p. 152). Being part of the CSP community, I will keep welcoming and celebrating the new ideas that Marilia Sá Carvalho, Luciana Dias de Lima, and Luciana Alves will certainly implement, assuring that CSP continues on its trajectory as one of the most important journals in our area.

\section{Additional information}

ORCID: Cláudia Medina Coeli (0000-0003-17573940).
1. Mogensen JF. Science has an ugly, complicated dark side. And the coronavirus is bringing it out. Mother Jones 2020; 28 apr. https://www.moth erjones.com/politics/2020/04/coronavirusscience-rush-to-publish-retractions/.

2. Alon U. How to build a motivated research group. Mol Cell 2010; 37:151-2. 